\title{
Induced Chromosome Deletion in a Williams-Beuren Syndrome Mouse Model Causes Cardiovascular Abnormalities
}

\author{
Craig J. Goergen ${ }^{a}$ Hong-Hua Li ${ }^{b}$ Uta Francke ${ }^{b}$ Charles A. Taylor ${ }^{a}$ \\ Departments of a Bioengineering and ${ }^{b}$ Genetics, Stanford University School of Medicine, Stanford, Calif., USA
}

\section{Key Words}

Aorta $\cdot$ Arterial stiffness $\cdot$ Biomechanics $\cdot$ Blood pressure $\cdot$

Elastin $\cdot$ Media $\cdot$ Strain $\cdot$ Ultrasound $\cdot$ Williams-Beuren

Syndrome

\begin{abstract}
Aims: The Williams-Beuren syndrome (WBS) is a genetic disorder caused by a heterozygous $\sim 1.5-\mathrm{Mb}$ deletion. The aim of this study was to determine how the genetic changes in a Wbs mouse model alter Eln expression, blood pressure, vessel structure, and abdominal aortic wall dynamics in vivo. Methods: Elastin (ELN) transcript levels were quantified by qRT-PCR and blood pressure was measured with a tail cuff system. M-mode ultrasound was used to track pulsatile abdominal aortic wall motion. Aortas were sectioned and stained to determine medial lamellar structure. Results: ELN transcript levels were reduced by $38-41 \%$ in Wbs mice lacking one copy of the ELN gene. These mice also had a 10-20\% increase in mean blood pressure and significantly reduced circumferential cyclic strain $(p<0.001)$. Finally, histological sections showed disorganized and fragmented elastin sheets in Wbs mice, but not the characteristic increase in lamellar units seen in $\mathrm{Eln}^{+/-}$mice. Conclusions: The deletion of Eln in this Wbs mouse model results in lower gene expression, hypertension, reduced cyclic strain, and fragmented
\end{abstract}

elastin sheets. The observation that the number of medial lamellar units is normal in Wbs deletion mice, which is in contrast to $\mathrm{El}^{+/-}$mice, suggests other genes may be involved in vascular development.

Copyright $\odot 2010$ S. Karger AG, Basel

\section{Introduction}

The Williams-Beuren syndrome (WBS), a complex genetic disorder with specific cardiovascular, cognitive, and behavioral manifestations, is caused by a heterozygous $\sim 1.5-\mathrm{MB}$ pair deletion on chromosome 7q11.23. This deletion is caused by the misalignment during meiosis of large region-specific low-copy repeat elements flanking the WBS critical region (WBSCR), leading to nonallelic homologous recombination [1-3]. Affected individuals have difficulty visualizing complete pictures, are commonly diagnosed with attention deficit disorder, and typically have mean full-scale intelligence quotients of 56 [4]. Other clinical characteristics, about which several thorough review articles have been published $[5,6]$, include distinctive facial features [7], social disinhibition [8], hyperacusis [9], hypertension [10], and supravalvular aortic stenosis (SVAS) or narrowing of large elastic arteries [11]. Histological characterization of arterial vessel

Dr. Craig J. Goergen

James H. Clark Center, Room E350

318 Campus Drive

Stanford, CA $94305-5431$ (USA)

Tel. +1 650498 5316, Fax +1 650725 9082, E-Mail cgoergen@ stanford.edu 
walls of WBS patients with SVAS showed disorganized lamellar structures, fragmented elastic fibers, and hypertrophy of smooth muscle cells [12]. Previous work has indicated that the increased risk of hypertension is likely due to this large arterial vessel remodeling that occurs during vascular development $[13,14]$. Some WBS patients even present smooth segmental narrowing of the abdominal aorta with concomitant stenosis at the origins of the renal arteries [15]. These vascular stenoses have been associated with deletions or disruptions within the elastin (ELN) gene $[7,11]$. Because of the distinct set of clinical features and relatively small number of affected genes, WBS has become a common disorder for the study of genotype-phenotype correlations in microdeletion syndromes [16].

Knockout (KO) mouse models are often generated to gain insight into gene function. The entire WBSCR is conserved in mice on chromosome band 5G2 in reverse orientation with respect to the centromere $[17,18]$. The Francke laboratory recently developed a mouse model that mimics the WBS heterozygous deletion seen in humans [19]. Two mouse strains were generated, each carrying half of the Wbscr deletion. Mice that contain the entire deletion were produced by crossing mice with the two half deletion genotypes. The two deletions in these mice are in trans and, therefore, do not exactly reproduce the contiguous deletion seen in WBS. Yet, as far as gene dosage is concerned, mice with both half deletions are a model for the human WBS deletion with the single exception that the Limk1 gene is inactivated on both chromosomes [19]. According to their location with respect to the centromere of mouse chromosome 5, the two half deletions were named proximal deletion (PD) and distal deletion (DD), while $\mathrm{D} / \mathrm{P}$ represents the double deletion. While the exact functions of all genes within the WBS region are not known, the gene that encodes the elastin molecule (Eln) in the DD region has been studied extensively $[16,20]$. Elastin is synthesized by smooth muscle cells and provides blood vessels with the ability to reversibly extend during the cyclic loading of the cardiac cycle [21]. Initially secreted as a monomer called tropoelastin, it is eventually organized into a polymer that forms concentric rings of elastic lamellae within the medial layer of the vessel wall. Each elastic lamella surrounds a layer of smooth muscle cells, forming a lamellar unit [22], which provide the resilience arteries need to expand during cardiac systole and recoil during diastole. Since the Eln gene falls within the distal section of the Wbs region, $\mathrm{DD}$ and $\mathrm{D} / \mathrm{P}$ mice have only one copy of the ELN gene.
Mice hemizygous for only the ELN gene $\left(E \mathrm{ln}^{+/-}\right)$have previously been created to determine the effect of elastin loss on vascular development [23]. By comparing vessel mechanics with blood pressure in $E l^{+/-}$mice, it has been shown that cardiac and vascular development is physiologically coupled [24]. Eln hemizygosity in both mice and humans induced a compensatory increase in the number of elastic lamellae created during arterial development $[23$, 25]. In humans, this results in an increased risk of obstructive vascular disease. Further research with $\mathrm{Eln}^{+/-}$mice found the animals to be stably hypertensive from birth [26] with slightly smaller and stiffer arteries [27] compared to wild-type littermates (WT-Eln). Hypertension and an increase in the number of lamellar units, both characteristics of human elastin arteriopathy, may be developmental adaptations to normalize vascular perfusion and circumferential vessel strain. There have been no reports of segmental stenoses in $\mathrm{Eln}^{+/-}$mice, an important difference from the human disease, and previous research reports strongly implicate Eln as a causal gene for SVAS and essential hypertension. Thus, we hypothesize that a vascular phenotype similar to $\mathrm{Eln}^{+/-}$mice will be seen in Wbs mice, leading to observable changes in large elastic arteries.

The purpose of this study was to determine how the genetic changes in this Wbs mouse model alter Eln expression, blood pressure, vessel structure, and abdominal aortic wall dynamics in vivo. The deletion strategy used to create Wbs mice allowed us to gain a greater understanding of which genes likely produce an observed phenotype, as $\mathrm{D} / \mathrm{P}$ mice could be compared to littermates that are either wild-type (WT-Wbs) or carry one of the half-deletions (DD or PD). Comparing $E l^{+/-}$to Wbs deletion mice also provides insight into the differences between a single gene $\mathrm{KO}$ and a multigene chromosomal deletion. Using a quantitative real-time polymerase chain reaction (qRT-PCR) technique to measure Eln transcript levels, a non-invasive tail cuff blood pressure system, a small animal ultrasound system to track aortic wall motion throughout the cardiac cycle, and histological analysis to quantify differences in medial lamellar structure, a correlation was noted between a portion of the Wbscr deletion and reduced $E \ln$ levels, increased blood pressure, stiffer blood vessels, and lamellar unit malformation.

\section{Materials and Methods}

The investigation conforms with the Guide for the Care and Use of Laboratory Animals published by the US National Institutes of Health (NIH publication No. 85-23, revised 1996). All 
experiments were conducted in accordance with the Institution's ethical guidelines and with local Institutional Animal Care and Use Committee approval.

\section{Animal Models}

Six different groups of mice were used in this study for a total of $\mathrm{n}=103$, and all mice were bred on a mixed C57BL/6J and 129/ Sv background. Wbs mice were predominantly C57BL/6J ( 85\% C57BL/6J vs. $\sim 15 \% 129 / \mathrm{Sv}$ ) [19], while $E \ln ^{+/-}$were mostly $129 / \mathrm{Sv}$. Male and female mice were included in both groups. Mice used for the in vivo portions of this study were between 21 and 42 weeks old with the following means \pm SD: WT-Wbs $=32.1 \pm 6.3$; WT$E l n=24.8 \pm 0.2 ; \mathrm{PD}=31.0 \pm 6.3 ; \mathrm{DD}=31.9 \pm 4.6 ; \mathrm{D} / \mathrm{P}=32.0$ \pm 7.5 , and $E \ln ^{+/-}=24.8 \pm 0.2$ weeks. Eln ${ }^{+/-}$and WT-Eln mouse body weights were significantly lower than all others, likely due to the different genetic background ( $p<0.05$ ), and PD, DD, and $\mathrm{D} / \mathrm{P}$ mice weighed less than WT-Wbs littermates: $\mathrm{WT}-\mathrm{Wbs}=37.3$ \pm 6.0; WT-Eln $=26.9 \pm 2.6 ; \mathrm{PD}=36.3 \pm 6.6 ; \mathrm{DD}=34.9 \pm 5.3$; $\mathrm{D} / \mathrm{P}=33.5 \pm 6.6$, and $E l^{+/-}=26.9 \pm 4.1 \mathrm{~g}$. Weight reduction was significant for $\mathrm{D} / \mathrm{P}$ when compared to WT-Wbs $(\mathrm{p}<0.05)$ and agrees with reported growth delays and short stature in this Wbs model [19]. Wbs mice have been kept alive for $>2$ years, with no instances of early death or unexpected morbidity later in life [unpubl. data]. Life expectancy is also normal for $E \ln ^{+/-}$mice [26]. As described previously, tail clipping was performed within 4 weeks of birth to determine the genotype of each mouse using PCR and appropriate primers $[19,20]$.

\section{$R N A$ Isolation and $q R T-P C R$}

To determine whether any of these heterozygous deletions result in a corresponding reduction in Eln transcription, 16 mice (3 WT-Wbs, 4 PD, $4 \mathrm{DD}$, and $5 \mathrm{D} / \mathrm{P}$ ) from three different litters were euthanized on postnatal day 7 (p7) and the visceral organs of the thorax were isolated and homogenized (similar tissue was used for Eln RNA extraction in previous research [23]). RNA extraction was performed using TRIzol (Invitrogen) according to the manufacturer's instructions. Total RNA was quantified with a spectrophotometer, and cDNA from each sample was synthesized from $2 \mu \mathrm{g}$ of RNA with SuperScript II (Invitrogen). After diluting the cDNA $1: 100,5 \mu$ l were used as template for qRT-PCR using SYBR Green Mix (Applied Biosystems). Typically, 25- $\mu$ l reactions consisting of $5 \mu \mathrm{lcDNA}$ (1:100), $12.5 \mu \mathrm{l}$ SYBR Green Master Mix, $2 \mu \mathrm{l}$ primer (10 $\mathrm{nM}$, forward and reverse), and $5.5 \mu \mathrm{l}$ water were used. Each sample was analyzed in triplicate in an ABI5700 thermocycler (Applied Biosystems). Threshold cycle values were set manually and analyzed using the comparative method (User Bulletin 2; Applied Biosystems). Amplification of Rps28 transcripts served as RNA control for relative quantification, with primers as described previously [28].

\section{Blood Pressure Measurement}

We measured systolic, mean, and diastolic blood pressure in conscious mice on three separate instances using a tail cuff system (BP 2000 system; Visitech Systems, Apex, N.C., USA). Mice were held in a black magnetic box on a heated stage. Multiple sessions allowed for each mouse to be trained and improved measurement consistency. At least 10 readings were made for each mouse $(\mathrm{n}=$ 7-9 per group).

\section{Ultrasound}

All mice were imaged in a supine position with the ultrasound transducer placed directly on the abdomen in an anteroposterior projection over the infrarenal aorta ( $n=7-10$ per group). We removed abdominal hair from each mouse with a depilatory cream. Similar to previous work, M-mode images tracking wall motion were collected at 2-4 discrete locations midway between the renal arteries and iliac bifurcation [29]. The diminutive vessels and rapid heart rates in rodents required a transducer-stabilizing system consisting of a heated platform to maintain body temperature and a transducer mount with an integrated rail system (VisualSonics, Toronto, Ont., Canada). The ultrasound system used (Vevo770; VisualSonics) was specifically designed for the high-resolution needs of small animal imaging with a high transducer frequency (40 MHz, transducer 704). All animals were anesthetized with $1.75-2 \%$ isoflurane in $1 \mathrm{l} / \mathrm{min}$ of $\mathrm{O}_{2}$ during ultrasound procedures.

\section{Image Data Analysis and Strain Quantification}

An average of 12 cardiac cycles was calculated from each mouse using the M-mode images. Adobe Photoshop CS (version 8.0; Adobe Systems, San Jose, Calif., USA) was used to measure anterior wall motion $\left(\delta_{\mathrm{a}}\right)$, posterior wall motion $\left(\delta_{\mathrm{p}}\right)$, systolic diameter $\left(D_{s}\right)$, and diastolic $\left(D_{d}\right)$ diameter. Using these measurements and assuming uniform strain around the vessel, the circumferential component of the Green-Lagrange strain tensor is [30]:

$$
E_{\theta \theta}=\frac{1}{2}\left(\left(\frac{D_{s}}{D_{d}}\right)^{2}-1\right)=\frac{1}{2}\left(\left(\frac{\delta_{a}+\delta_{p}+D_{d}}{D_{d}}\right)^{2}-1\right) \times 100 \%
$$

This definition of cyclic circumferential strain assumes the diameter at end diastole is the unloaded reference dimension. It also characterizes deformations independent of rigid body motion and takes into account the nonlinear terms that are ignored when using a small deformation assumption. Aortic circumferential strain for each genotype was estimated and presented as a percentage $(\times 100 \%)$.

Pressure Strain Elastic Modulus and Vessel Stiffness

As defined previously [31], a vessel's in vivo pressure strain elastic modulus (or $\mathrm{E}_{\mathrm{p}}$ ) is defined as:

$$
E_{p}=K \times \frac{P_{s}-P_{d}}{\left(D_{s}-D_{d}\right) / D_{d}}\left(10^{5}\right) P a
$$

Likewise, a general metric for vessel stiffness $(\beta)$ is defined as [32]:

$$
\beta=\frac{\ln \left(P_{s} / P_{d}\right)}{\left(D_{s}-D_{d}\right) / D_{d}}
$$

In these definitions $\mathrm{P}_{\mathrm{s}}$ is the mean systolic pressure, $\mathrm{P}_{\mathrm{d}}$ is the mean diastolic pressure (if pressures are measured in $\mathrm{mm} \mathrm{Hg}, \mathrm{K}$ is a constant of 133.3).

\section{Histology}

Mice were sacrificed with $0.4 \mathrm{mg}$ of tribromoethanol per gram of body mass ( $n=3-5$ per group). The aortas were exposed and pressure perfused with $10 \%$ formalin at $100 \mathrm{~mm} \mathrm{Hg}$ for $5 \mathrm{~min}$. The ascending thoracic, descending thoracic, and infrarenal abdominal aorta were harvested and imbedded in paraffin. Axial slices $5 \mu \mathrm{m}$ in thickness were stained with elastic van-Gieson to visualize elastic lamina and Masson's trichrome for collagen. These ax- 


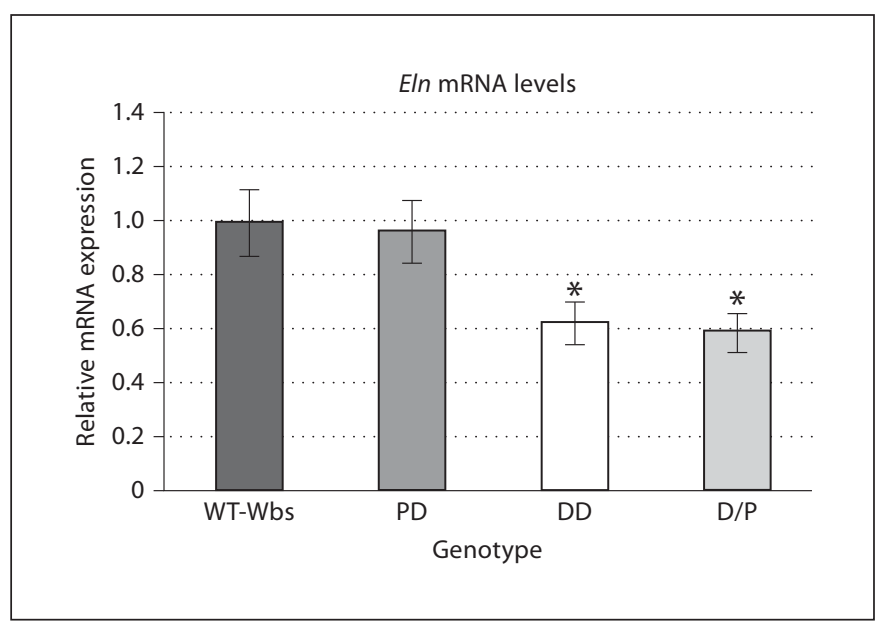

Fig. 1. Relative Eln transcript levels in p7 mice from each Wbs genotype. The data have been normalized such that the mean of the WT-Wbs group is $1.0 \pm 0.12$. Eln transcripts in DD and D/P mice are significantly reduced compared to combined WT-Wbs and PD levels $\left(n=3-5\right.$ per group; $\left.{ }^{*} \mathrm{p}<0.03\right)$. Means \pm SE.

ial cross-sections were imaged with a Leica DM IL inverted microscope (Meyer Instruments, Houston, Tex., USA) with a total magnification of $\times 400$ under a bright field. We acquired images using QCapture Pro 5.1 (QImaging, Surrey, B.C., Canada). The number of medial lamellar units (MLUs) was quantified at 10 locations around the circumference using Adobe Photoshop CS (Adobe Systems).

\section{Statistics}

All data are presented as means \pm SD or SE. Statistical analysis was performed using ANOVA with a post hoc Tukey-Kramer honestly significant difference comparison between multiple groups (JMP version 7; SAS, Cary, N.C., USA). Values of $\mathrm{p}<0.05$ were considered significant.

\section{Results}

\section{Reduced Eln Expression in DD and D/P Mice}

The levels of Eln transcript, as determined from the experimental triplicates of each mouse by quantitative RT-PCR, were distinctly different depending on Eln gene dosage. On average, Eln levels in PD mice $(\mathrm{n}=4)$ were similar to WT-Wbs $(\mathrm{n}=3)$, while Eln levels in DD $(\mathrm{n}=4)$ and $\mathrm{D} / \mathrm{P}(\mathrm{n}=5)$ mice showed reductions of 38 and $41 \%$, respectively (fig. 1). This reduction seen in mice with only one copy of the Eln gene was significant for both groups when compared to mice with two copies of the Eln gene (PD and WT-Wbs combined; $\mathrm{p}<0.03$ ). These data are consistent with previously reported quantitative mRNA
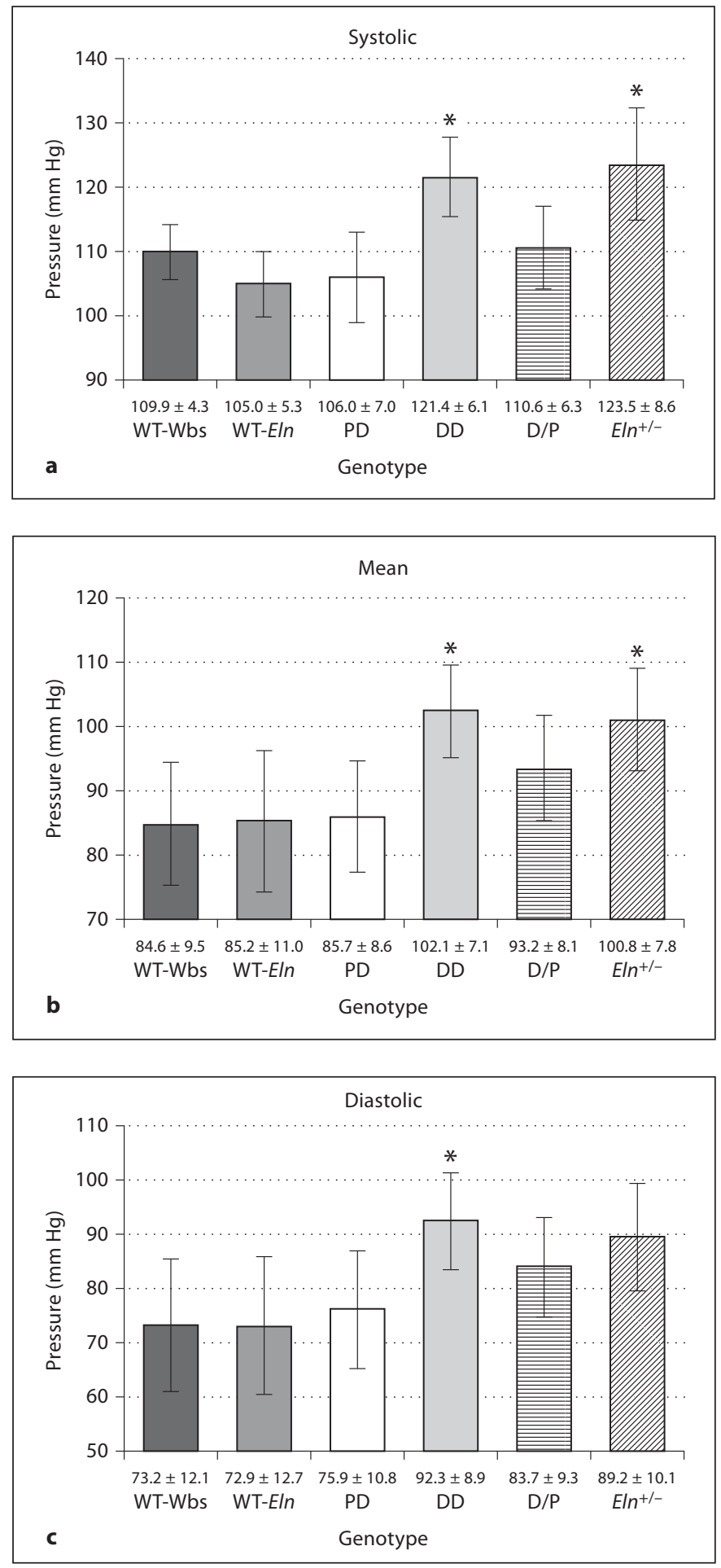

Fig. 2. Systolic (a), mean (b), and diastolic (c) blood pressure in conscious mice from each genotype using a tail cuff measurement system ( $\mathrm{n}=7-10$ for each group). DD and $E \mathrm{ln}^{+/-}$have significantly elevated systolic and mean pressures, with DD also showing increased diastolic pressure compared to wild-type littermates $\left({ }^{*} \mathrm{p}<0.05\right) . \mathrm{D} / \mathrm{P}$ mice have elevated mean and diastolic pressure, but these increases did not reach significance. Means \pm SD. 

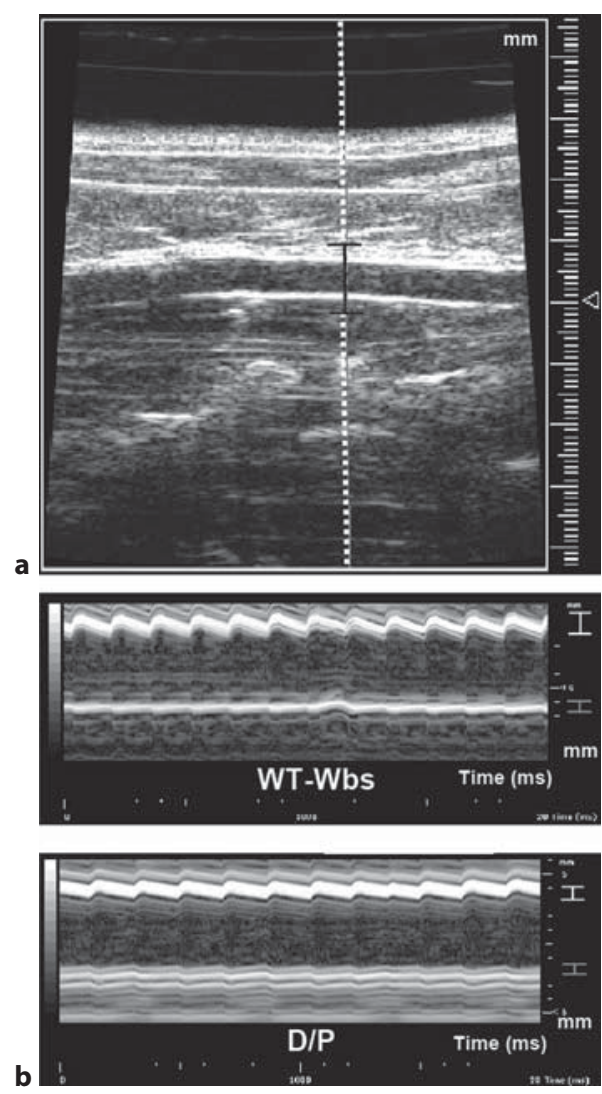

Fig. 3. a Anteroposterior projection B-mode ultrasound image of the abdominal aorta. One trajectory from the image is selected (dotted line) through a selected depth (black bracket) to track aortic motion. b M-mode image highlighting anterior wall motion (white bracket) and posterior wall motion (gray bracket) in both WT-Wbs and D/P mice. c Anterior (a) and posterior (p) aortic wall motion with schematic showing distances defined $\delta_{\mathrm{a}}$ and $\delta_{\mathrm{p}}$. DD, $\mathrm{D} / \mathrm{P}$, and $\mathrm{Eln}^{+/-}$mice all showed significantly reduced anterior

Northern analysis, showing a $40-50 \%$ reduction of $E \ln$ expression in $\mathrm{Eln}^{+/-}$mice [23].

\section{Increased Blood Pressure in DD and $\mathrm{Eln}^{+-}$Mice}

Blood pressure levels, known to be increased in $\mathrm{Eln}^{+/-}$ mice [26], were measured in conscious mice from all six groups (fig. 2). Both DD and $\mathrm{Eln}^{+/-}$mice had significantly elevated systolic and mean pressures compared to their wild-type littermates $(\mathrm{p}<0.05) . \mathrm{D} / \mathrm{P}$ mice had slightly elevated mean and diastolic pressure, but these increases did not reach significance. These measurements corresponded to pulse pressures of the following means $\pm \mathrm{SD}$ :
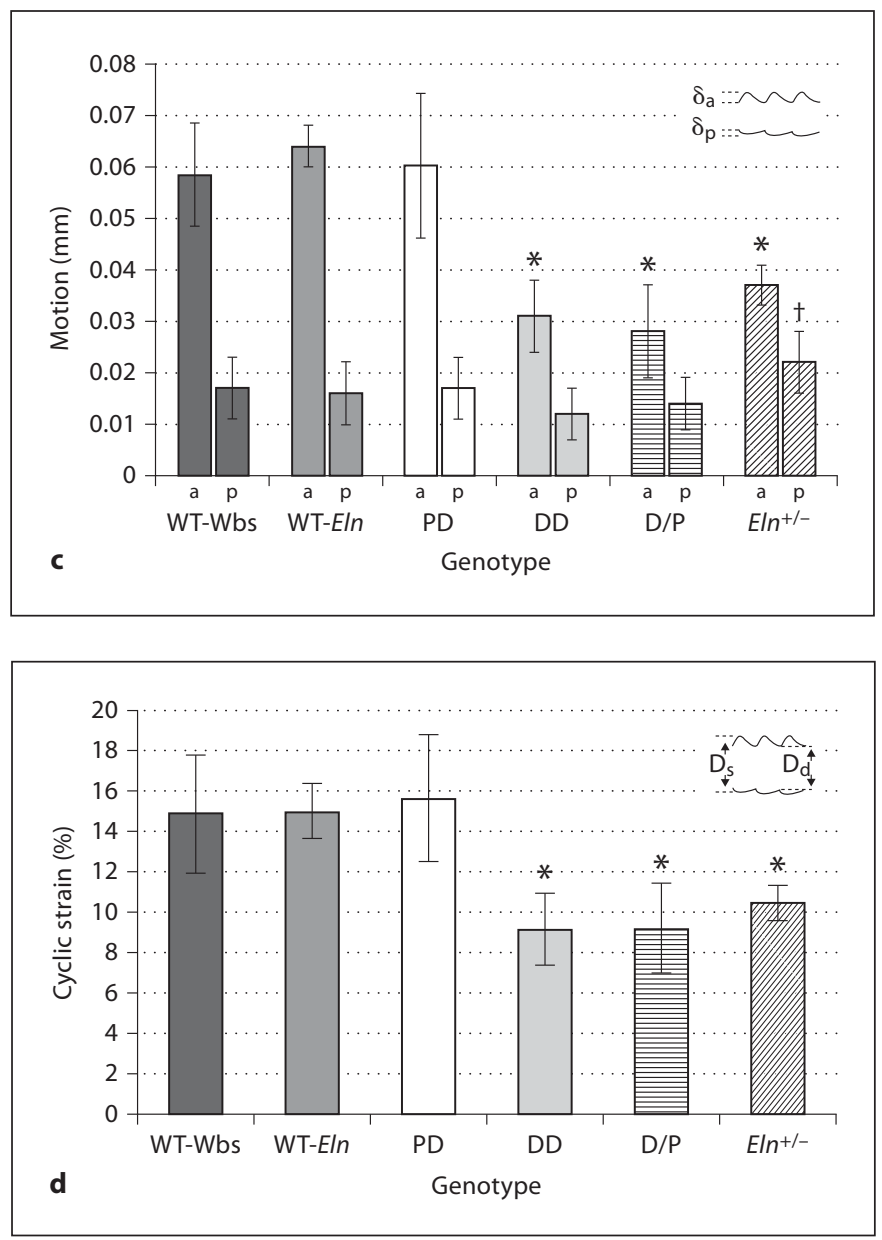

wall motion compared to wild-type littermates $\left({ }^{*} \mathrm{p}<0.001\right)$. Interestingly, $\mathrm{Eln}^{+/-}$mice had significantly greater posterior wall motion than DD and D/P mice $\left({ }^{\dagger} \mathrm{p}<0.05\right)$. d Circumferential cyclic Green-Lagrange strain with schematic of aortic motion showing maximum systolic $\left(D_{s}\right)$ and minimum diastolic $\left(D_{d}\right)$ diameters. Strain in DD, D/P, and $E l n^{+/-}$mice were significantly reduced compared to wild-type littermates $\left({ }^{*} \mathrm{p}<0.001\right)$. Means $\pm \mathrm{SD}$.

WT-Wbs $=36.7 \pm 11.2 ; \mathrm{WT}-E \ln =32.1 \pm 10.7 ; \mathrm{PD}=30.2$ $\pm 10.8 ; \mathrm{DD}=29.1 \pm 8.5 ; \mathrm{D} / \mathrm{P}=26.9 \pm 8.7$, and $\mathrm{Eln}^{+/-}=$ $34.3 \pm 11.4 \mathrm{~mm} \mathrm{Hg}$.

\section{Reduced Wall Motion and Circumferential Cyclic Strain in DD and D/P Mice}

Ultrasound provided information about the motion and strain experienced by the aorta in vivo. Exemplary Bmode and M-mode ultrasound images of the abdominal aorta are shown in figure $3 a$ and $b$, respectively. Both anterior and posterior wall motion over several cardiac cycles can be seen in the M-mode tracings (fig. 3b). Across 

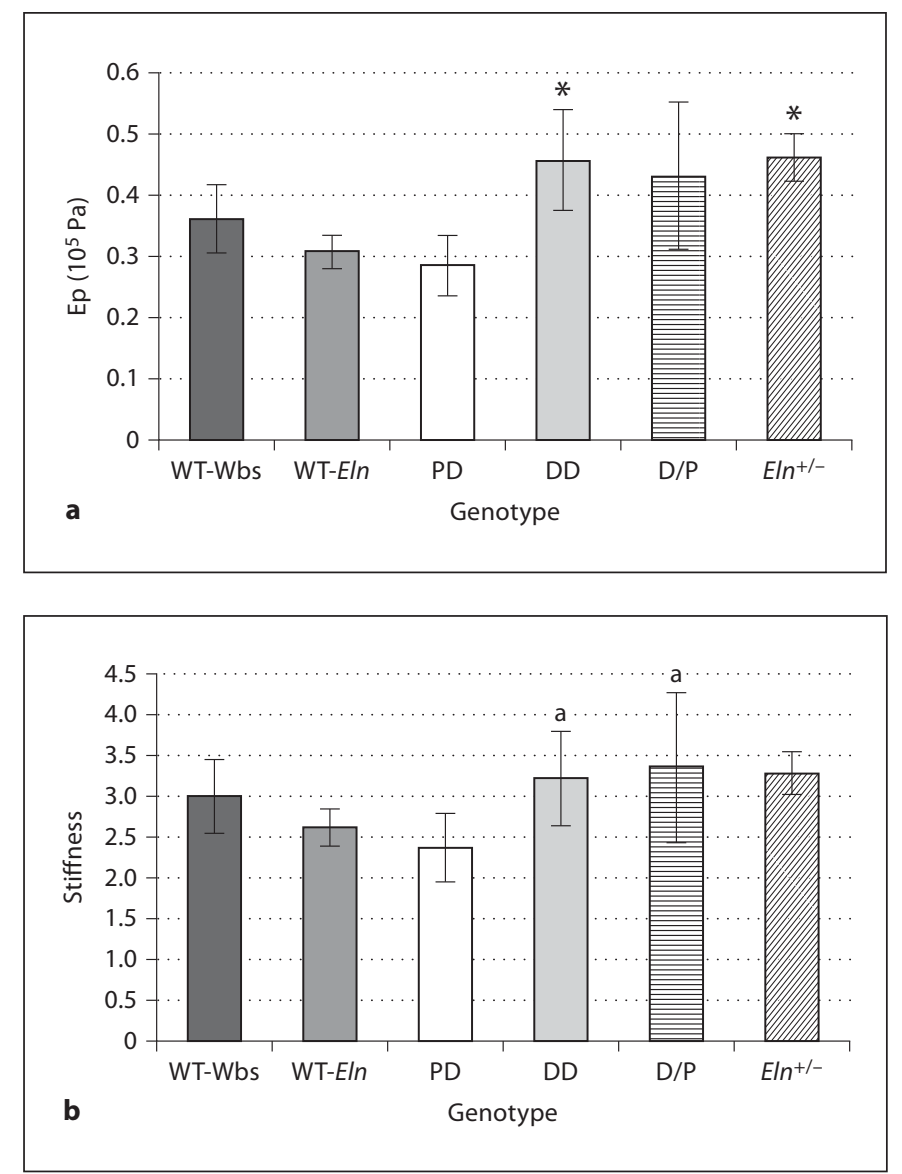

Fig. 4. Pressure-strain elastic modulus $\left(\mathrm{E}_{\mathrm{p}} ; \mathbf{a}\right)$ and aortic stiffness (b) for each group. DD and $E n^{+/-}$mice had significantly greater $\mathrm{E}_{\mathrm{p}}$ values compared to wild-type littermates (* $\left.\mathrm{p}<0.05\right)$. No groups had stiffness values that differed significantly from their wild-type littermates, but DD and D/P mice did have greater vessel stiffness values compared to PD mice ( $\left.{ }^{a} p<0.05\right)$. Means \pm SD.

all groups, it is obvious that the amount of anterior wall motion was greater than posterior wall motion. This may be due to differences in external tissue support and agrees well with previously published data using this technique [29]. Figure $3 \mathrm{c}$ shows the average anterior and posterior wall motion for all four genotypes. Anterior wall motion was significantly reduced in $\mathrm{DD}, \mathrm{D} / \mathrm{P}$, and $\mathrm{Eln}^{+/-}$mice compared to wild-type littermates $(\mathrm{p}<0.001)$ : anterior $(\mathrm{mm}) \mathrm{WT}-\mathrm{Wbs}=0.059 \pm 0.01$; WT-Eln $=0.064 \pm 0.004$; $\mathrm{PD}=0.060 \pm 0.01 ; \mathrm{DD}=0.031 \pm 0.007 ; \mathrm{D} / \mathrm{P}=0.028 \pm$ 0.009 , and $E \ln ^{+/-}=0.037 \pm 0.004$. Likewise, posterior motion was also reduced in the $\mathrm{DD}$ and $\mathrm{D} / \mathrm{P}$ mice compared to $\mathrm{WT}$-Wbs, yet this difference was not significant as the overall amount of posterior motion was small: posterior $(\mathrm{mm}) \mathrm{WT}-\mathrm{Wbs}=0.017 \pm 0.006$; WT-Eln $=0.016 \pm 0.006$; $\mathrm{PD}=0.017 \pm 0.006 ; \mathrm{DD}=0.012 \pm 0.005 ; \mathrm{D} / \mathrm{P}=0.014$ \pm 0.005 , and $E \ln ^{+/-}=0.022 \pm 0.006$. Interestingly, posterior motion in $\mathrm{Eln}^{+/-}$mice was higher than in all other groups, with a significant increase versus $\mathrm{DD}$ and $\mathrm{D} / \mathrm{P}$ mice $(p<0.05)$. Finally, circumferential cyclic Green-Lagrange strain, a mechanical characteristic of vessel loading defined in equation 1 , was significantly reduced in DD, D/P, and $\mathrm{Eln}^{+/-}$mice compared to wild-type littermates (fig. $3 \mathrm{~d}, \mathrm{p}<0.001$ ): circumferential strain (\%) WTWbs $=14.9 \pm 2.9 ;$ WT-Eln $=15.0 \pm 1.4 ; \mathrm{PD}=15.6 \pm 3.1$; $\mathrm{DD}=9.1 \pm 1.8 ; \mathrm{D} / \mathrm{P}=9.2 \pm 2.3$, and $\mathrm{Eln}^{+/-}=10.4 \pm 0.9$.

\section{Increased Pressure Strain Elastic Modulus and Vessel Stiffness}

Combining ultrasound and pressure measurements allowed for the estimation of the pressure strain elastic modulus $\left(\mathrm{E}_{\mathrm{p}}\right)$ and vessel stiffness $(\beta)$. DD and $\mathrm{Eln}^{+/-}$mice both had significantly increased $\mathrm{E}_{\mathrm{p}}$ values (equation 2 ) compared to wild-type littermates (fig. $4 \mathrm{a} ; \mathrm{p}<0.05$ ): $\mathrm{E}_{\mathrm{p}}$ $\left(10^{5} \mathrm{~Pa}\right) \mathrm{WT}-\mathrm{Wbs}=0.362 \pm 0.055$; WT-Eln $=0.308 \pm$ $0.027 ; \mathrm{PD}=0.285 \pm 0.050 ; \mathrm{DD}=0.457 \pm 0.082 ; \mathrm{D} / \mathrm{P}=$ $0.431 \pm 0.119$, and $E \ln ^{+/-}=0.462 \pm 0.038$. D/P was also increased, but not significantly compared to WTWbs. Finally, vessel stiffness (equation 3) values were larger in $E l n$ heterozygous mice (fig. $4 \mathrm{~b}$ ): vessel stiffness $\mathrm{WT}-\mathrm{Wbs}=3.00 \pm 0.46$; WT- $E \ln =2.62 \pm 0.23$; PD = $2.37 \pm 0.42 ; \mathrm{DD}=3.22 \pm 0.58 ; \mathrm{D} / \mathrm{P}=3.35 \pm 0.93$, and $\mathrm{Eln}^{+/-}=3.29 \pm 0.27$. These increases were not significant compared to wild-type littermates, but the increases were larger in $\mathrm{DD}$ and $\mathrm{D} / \mathrm{P}$ mice compared to $\mathrm{PD}$ mice $(\mathrm{p}<$ 0.05).

\section{Histological Sections Show Malformed ELN Sheets in $D D$ and $D / P$ Mice}

Vascular histology and morphologic examination provided insight into the structure of the aorta. No segmental stenoses were observed in the thoracic or abdominal aorta in any mouse. Representative pressure-perfused sections of the abdominal aortic wall stained with elastic van-Gieson (fig. 5) as well as color images of elastic van-Gieson and Masson's trichrome staining (online suppl. figure, www.karger.com/doi/10.1159/000316808) showed disorganized and more fragmented elastin sheets in $\mathrm{DD}$ and $\mathrm{D} / \mathrm{P}$ compared to WT-Wbs and PD. Interestingly, the number of lamellar units differed between mice with only one copy of the Eln gene (table 1). Only Eln ${ }^{+/-}$ mice had a significant increase in the number of lamellar units compared to wild-type littermates (ascending tho- 
Table 1. Number of MLUs for all six genotypes as means \pm SD (number of animals) in the ascending thoracic, descending thoracic, and infrarenal abdominal aorta

\begin{tabular}{lcll}
\hline Genotype & $\begin{array}{l}\text { Ascending } \\
\text { thoracic aorta }\end{array}$ & $\begin{array}{l}\text { Descending } \\
\text { thoracic aorta }\end{array}$ & $\begin{array}{l}\text { Infrarenal } \\
\text { abdominal aorta }\end{array}$ \\
\hline WT-Wbs & $7.3 \pm 1.1(4)$ & $4.9 \pm 0.4(4)$ & $3.3 \pm 0.3(8)$ \\
WT-Eln & $7.8 \pm 0.6(4)$ & $5.3 \pm 0.1(4)$ & $3.4 \pm 0.1(4)$ \\
PD & $7.3 \pm 0.8(4)$ & $4.9 \pm 0.4(4)$ & $3.2 \pm 0.5(8)$ \\
DD & $7.6 \pm 0.9(4)$ & $5.5 \pm 0.2(4)$ & $3.4 \pm 0.1(7)$ \\
D/P & $7.2 \pm 0.8(5)$ & $5.4 \pm 0.2(5)$ & $3.4 \pm 0.3(9)$ \\
Eln $^{+/-}$ & $10.1 \pm 0.5(8)^{*}$ & $6.6 \pm 0.4(8)^{*}$ & $4.7 \pm 0.4(8)^{*}$ \\
\hline
\end{tabular}

$E \mathrm{In}^{+/-}$mice show an increase in the number of MLUs at all three locations when compared to all other groups $\left({ }^{*} \mathrm{p}<0.01\right)$.

racic aorta $29.5 \%$, descending thoracic aorta $24.5 \%$, and infrarenal abdominal aorta $38.2 \%$; $<0.01$ compared to all other groups). The DD and D/P mice did not show an increase in the MLU number.

\section{Discussion}

Although the cause of WBS, a recurrent deletion of $\sim 1.5-\mathrm{Mb}$ pairs on chromosome $7 \mathrm{q} 11.23$, was originally discovered in 1993 [7], the contributions of specific genes within the deletion to the phenotype have not been clearly defined. A recently developed Wbs mouse model has provided new insight into the study of this neurodevelopmental disorder. It has given researchers the ability to correlate phenotypic changes seen in these mice to regions within the WBS deletion. Others have developed several different animal models of genetic vascular disease, providing intriguing insight into the relationship between gene expression and vascular development. Mouse models, specifically, have underscored the prominent role of the elastic matrix in the morphogenesis and homeostasis of the vessel wall [33]. For example, a fibulin-5 KO mouse model has been used to show that defective organization and stabilization of elastic fibers produces stiffer arteries [34]. Other research has focused on the Eln gene because of its known effects on the cardiovascular system and linkage to SVAS $[26,33]$. The $E l n^{+/-}$mice used in this study were developed over a decade ago and have been extensively analyzed by others $[20,23,27,35]$. The focus of this study was to determine how the different chromosomal
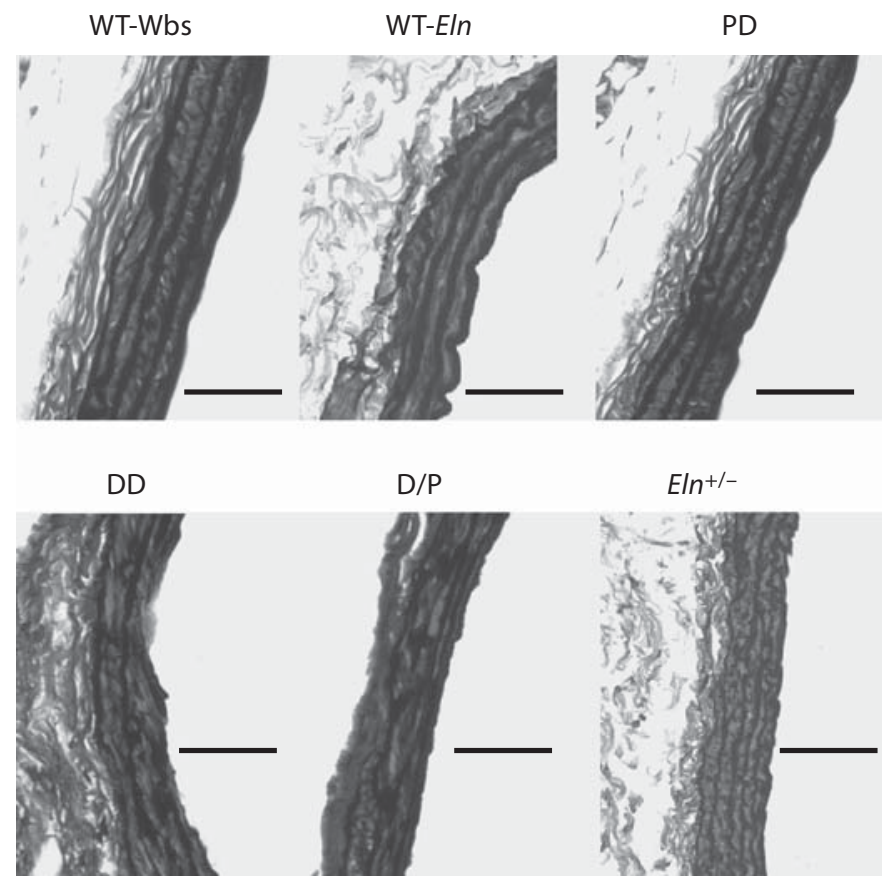

Fig. 5. Representative axial aortic histological sections from the abdominal aorta for each genotype. Dark elastin sheets in the media are easily seen forming lamellar units. The aortic lumen is on the right of each image, and the adventitial layer, mainly composed of collagen, is on the left. More disorganized and jagged elastin sheets in DD and D/P vessels are obvious compared to WTWbs and PD. Eln ${ }^{+-}$mice have more MLUs that appear to be thinner and more closely spaced, but are not as fragmented as DD and $\mathrm{D} / \mathrm{P}$ elastin sheets. Bars $=50 \mu \mathrm{m}$.

deletions in the new Wbs model affect the cardiovascular system by comparing them to wild-type littermates and to single-gene $\mathrm{KO} \mathrm{Eln}^{+/-}$mice.

We found reduced Eln transcript levels, determined by qRT-PCR, in mice that carry DD and D/P, suggesting that the amount of elastin produced during development is reduced. This was expected as the Eln gene lies within the distal portion of the $\mathrm{Wbs}$ deletion and is consistent with the reported $40-50 \%$ reduction of mRNA in $\mathrm{Eln}^{+/-}$mice [23]. We chose to use p7 mice because Eln expression is vital during this early period when elastic arteries are developing and structurally effective elastin deposition occurs [36]. While Eln mRNA levels may differ slightly between aortic tissue and whole thorax homogenate, we would expect the relative expression, with respect to the WT-Wbs group, to be similar for both. The reduction in Eln transcripts during development was likely a factor in the increased blood pressure levels, reduced in vivo cyclic strain, and more disorganized and frayed elastic sheets 
seen in these mice. Finally, while differences in strain backgrounds exist between the Wbs and $\mathrm{Eln}^{+/-}$mice, no differences were seen between WT-Eln and WT-WBS mice, suggesting that any changes are most likely caused by the genetic mutations themselves.

Previous research has indeed shown $E \mathrm{ln}^{+/-}$mice to be hypertensive, with a mean arterial pressure $28 \%$ higher than their wild-type counterparts [26]. This increase is already present in newborn mice [35] and persists throughout their lifetime without lowering life-expectancy [26]. The lower blood pressure levels reported here (fig. 2) are likely due to differences in methodology. We chose to use a non-invasive tail cuff system, which measures blood pressure in the tail, while others have used an invasive catheter system that can measure pressure directly in the aorta [35]. The cuff system has also been known to be sensitive to body temperature and positioning along the tail. Although the actual blood pressure measurements were slightly lower in our study, we found a similar $18.3 \%$ increase in mean pressure of $E l^{+/-}$mice, giving us confidence these single-gene-KO mice are hypertensive. Interestingly, a similar significant increase in mean blood pressure was only seen in DD mice (20.6\%) in comparison to the WT-Wbs group. Mean pressure in $\mathrm{D} / \mathrm{P}$ mice increased by only $10.1 \%$, suggesting a modifying effect of gene(s) within or near the PD region on blood pressure in these adult mice. In this regard, the NCF1 gene in humans, which encodes the p47 subunit of the NADPH oxidase and is sometimes included in the WBS deletion, has been shown to modify the risk of hypertension. More specifically, hypertension was significantly less prevalent in patients with WBS who had a deletion that included NCF1 [37]. While the presence of NCF1 in WBS patients is variable, the mouse homologue (Ncf1) is outside of both deletions in this Wbs mouse model (it is the next gene beyond the breakpoint Gtf2i in PD mice [19]). Therefore, Ncf1 is unlikely to have an impact on blood pressure in this model. The mechanism to explain the hypertension in DD mice is probably related to the loss of one copy of the Eln gene, but the cause of the nonsignificant increase seen in $\mathrm{D} / \mathrm{P}$ mice is likely more complex and will be the topic of future investigation.

In vivo ultrasound measurements provide insight into the motion of the vessel with supporting tissue and under physiologic pressure. Reduced aortic distention is consistent with previously published data for the abdominal aorta in $\mathrm{Eln}^{+/-}$mice when ex vivo compliance was compared at physiologic pressure levels $[26,27]$ and in vivo in newborn mice [35]. We found significantly decreased anterior and posterior wall motion in $\mathrm{DD}$ and $\mathrm{D} / \mathrm{P}$ mice.
Interestingly, $\mathrm{Eln}^{+/-}$mice had decreased anterior motion, but larger posterior motion than any other group $(0.022$ $\pm 0.006 \mu \mathrm{m})$. One possible explanation for this could be the fact that $\mathrm{Eln}^{+/-}$mice have more tortuous vessels, likely due to the offloading of longitudinal tension [38]. Thus, posterior motion may be increased if support of the abdominal aorta from the spine and back muscle is no longer directly posterior to the vessel.

Green-Lagrange circumferential cyclic strain, a metric that takes into account nonlinear terms, was used because relatively large strain values $(8-16 \%)$ were studied, making linear diameter strain measurements inaccurate. Our circumferential strain results for the WT-Wbs group $(14.9 \pm 2.9 \%)$ compared well to previously published reports for the normal murine abdominal (15.7 $\pm 2.5 \%)$ [29] and thoracic aorta (15.5 $\pm 3.3 \%)$ [35], giving us confidence that our data are accurate. The reduction in strain was similar for DD, D/P and $\mathrm{Eln}^{+/-}$mice, suggesting that aortic compliance is reduced in mice with less elastin in their large arteries and it is the reduced Eln levels that likely caused these dramatic changes in vascular dynamics. Because the vascular phenotype of PD mice is similar to WT-Wbs, this suggests that no other genes within the proximal region influence in vivo aortic motion.

We estimated aortic compliance by calculating the pressure-strain elastic modulus $\left(\mathrm{E}_{\mathrm{p}}\right)$ and aortic stiffness $(\beta)$, both of which combine blood pressure and wall motion data. As expected, mice from DD, D/P, and $E l^{+/-}$ groups all had larger $E_{p}$ and $\beta$ values compared to their wild-type littermates. Compared to clinical data from humans of varying age, our results were similar to male volunteers 5-15 years old [39]. These values increase with age, likely due to a combination of changing wall content (i.e. elastin degradation and increased collagen production) and increased atherosclerotic burden. In our study, this increase is likely due to a combination of hypertension and altered vascular development.

Finally, we saw an interesting difference between Wbs and $\mathrm{Eln}^{+-}$mice in aortic wall sections stained for elastin and collagen. While the numbers of MLUs in WT-Eln and $\mathrm{Eln}^{+-}$mice were slightly lower than previously published data [23], our histological images look similar and the percent increase of MLUs in $\mathrm{Eln}^{+/-}$mice was comparable (between 24.5 and $29.5 \%$ in the thoracic aorta). Thus, this difference is likely explained by variations in strain background or a slight disparity in what was defined as ascending and descending thoracic aorta. Others have hypothesized that with ELN insufficiency, vascular smooth muscle cells cannot produce enough elastin to withstand the pulsatile circumferential forces, suggesting 
Table 2. Summary of similarities and differences between Wbs mice, $E l^{+/-}$mice, SVAS patients, and WBS patients

\begin{tabular}{|c|c|c|c|c|c|c|}
\hline & \multicolumn{4}{|l|}{ Mice } & \multirow[t]{2}{*}{ Human WBS } & \multirow[t]{2}{*}{ Human SVAS } \\
\hline & PD Wbs & DD Wbs & $\mathrm{D} / \mathrm{P} \mathrm{Wbs}$ & $E \ln ^{+/-}$ & & \\
\hline Elastin gene expression & normal & reduced $38 \%$ & reduced $41 \%$ & reduced $40-50 \%[23]$ & reduced [16] & reduced [16] \\
\hline Mean blood pressure & normal & $\begin{array}{l}\text { increased by } \\
18 \mathrm{~mm} \mathrm{Hg}\end{array}$ & $\begin{array}{l}\text { increased by } 9 \mathrm{~mm} \mathrm{Hg} \\
\text { (non-significant) }\end{array}$ & increased by $16 \mathrm{~mm} \mathrm{Hg}$ & $\begin{array}{l}\text { increased in } 13 \% \\
\text { of patients [16] }\end{array}$ & $\begin{array}{l}\text { sometimes increased } \\
{[41]}\end{array}$ \\
\hline In vivo aortic strain & normal & reduced $6 \%$ & reduced $6 \%$ & reduced $5 \%$ & - & - \\
\hline Number of MLUs & normal & normal & normal & increased $25-38 \%$ & increased [25] & increased $[25,41]$ \\
\hline MLU structure & normal & $\begin{array}{l}\text { fragmented, } \\
\text { disorganized }\end{array}$ & $\begin{array}{l}\text { fragmented, } \\
\text { disorganized }\end{array}$ & thinner & $\begin{array}{l}\text { thinner, } \\
\text { fragmented [25] }\end{array}$ & $\begin{array}{l}\text { thinner, fragmented } \\
{[25,41]}\end{array}$ \\
\hline Aortic stenosis & no & no & no & no & often [16] & often [16] \\
\hline
\end{tabular}

that the increase in MLUs is a developmental adaptation to normalize wall tension [26]. While elastin and collagen fibers did appear more disorganized in DD and D/P mice, with frayed elastin sheets and inhomogeneous collagen distribution, the number of lamellar units was similar for all Wbs mice in the ascending thoracic, descending thoracic, and abdominal aorta. Compared to the DD and $\mathrm{D} / \mathrm{P}$ mice, we did not observe as much lamellar fragmentation and disorganized elastin in the aortas of $\mathrm{Eln}^{+/}$ mice. These disorganized and dispersed fragmented elastin fibers are similar to the aortic pathology often seen in human cases of WBS [25]. Thus, our results suggest that one or more genes within the DD region may affect vascular development and MLU formation by inhibiting the increase in layers seen in $\mathrm{Eln}^{+/-}$mice. Furthermore, the reduced aortic motion and cyclic circumferential strain cannot be attributed to an increase in lamellar units, as this phenotype was observed in DD, D/P, and $\mathrm{Eln}^{+/-}$mice. More likely, altered vessel dynamics can be attributed to an increased loading of collagen fibers in any vascular tissue with altered elastin structure. All of the above findings are summarized in table 2, with a comparison to SVAS and WBS patients.

Clinical reports have confirmed with intravascular ultrasound that WBS patients have diffusely narrowed and thick-walled stiff arteries, often lacking elastin [40]. These pathologies are hypothesized to be caused by smooth muscle hypertrophy in the medial layer, with abnormal elastic fibers and mild collagenization, as seen in several clinical cases [41-43]. These pathologic changes progress with age in humans, often reducing life expectancy. In animals, Eln expression and organization has been shown to alter the response of vessels to aging in $\mathrm{Eln}^{+/-}$mice [44]. Other clinical case reports have shown no difference in arterial lesions when patients with SVAS and WBS were compared ( $\mathrm{n}=2$ for both) [25], describing elastic fibers as thin, fragmented, and numerous in both diseases. While interesting, further work quantifying elastin structures in a larger number of WBS patients would help improve our understanding of the vascular malformations associated with this disease.

Due to the observed changes in the medial layer, innervation of the abdominal aorta or response to vasoactive hormones may also differ in Wbs mice. First, it has long been known that several different types of neurons innervate all three layers of the abdominal aorta, with abundant nerve endings in the adventitial layer. For example, in humans, cholinergic nerve fibers, known to be parasympathetic, are organized in two plexuses: a superficial layer localized in the adventitia and a deeper layer localized in the adventitial-medial transitional zone. In mice, cholinergic nerve fibers are organized in a single plexus in the adventitia [45]. Other receptor trunks make a stepwise course as they penetrate through the layered elastin sheets in the media [46]. Since vascular elastin does not form typical layered lamellar units in DD and $\mathrm{D} / \mathrm{P}$ mice, neuronal endings in this layer would likely have a different morphology, possibly affecting their function. Neural control mechanisms could also play a role in the development and maintenance of vascular elastic tissues. Future work will be needed to determine where these innervating structures are located and what role they play in the altered phenotypes observed in Wbs mice. Secondly, previous work has shown that the mouse aorta contracts when exposed to agonists of adrenergic, serotonergic, dopaminergic, and prostaglandin receptors [47]. Thus, future research could determine the ex vivo aortic response of $\mathrm{Wbs}$ mice to common vasoactive agonists and antagonists. 
In summary, mice that carry a deletion in the Eln gene (DD, D/P, and $E l^{+/-}$mice) have a less compliant aorta, likely due to reduced $E \ln$ transcription and morphological changes in wall structure. We did not observe an increase in the number of elastic lamellae within the medial layer in Wbs mice carrying one copy of the Eln gene, a characteristic that is seen in $\mathrm{Eln}^{+/-}$mice [23]. This difference may be due to one or more genes within the DD region affecting vascular development and lamellar formation, or uncharacterized variations between inbred strain backgrounds. These data provide further insight into the genetic relationship between $E l n$ levels, aortic stiffness, and the cardiovascular abnormalities associated with WBS.

\section{Acknowledgments}

The authors gratefully acknowledge Oscar Abilez for his help in quantifying histological images, Lisa Gunaydin, Zhiqiang Chen, and Karl Deisseroth for their help with the WBS mouse colony, Marlene Rabinovitch, Lingli Wang, and Dean Li for providing and genotyping the WT-Eln and Eln ${ }^{+/-}$mice, Andrew Patterson and Rani Agrawal for access to the blood pressure quantification system, and Joan Greve for her editing assistance.

This work was supported by the National Institute of Child Health and Human Development, National Institutes of Health (grant R01HD39927 to U.F.). A Robert and Ruth Halperin Stanford Graduate Fellowship and a National Science Foundation Graduate Research Fellowship supported C.J.G.

\section{References}

1 Bayes M, Magano LF, Rivera N, Flores R, Perez Jurado LA: Mutational mechanisms of Williams-Beuren syndrome deletions. Am J Hum Genet 2003;73:131-151.

-2 Peoples R, Franke Y, Wang YK, Perez-Jurado L, Paperna T, Cisco M, Francke U: A physical map, including a $\mathrm{BAC} / \mathrm{PAC}$ clone contig, of the Williams-Beuren syndrome-deletion region at 7q11.23. Am J Hum Genet 2000;66: $47-68$.

-3 Valero MC, de Luis O, Cruces J, Perez Jurado LA: Fine-scale comparative mapping of the human $7 \mathrm{q} 11.23$ region and the orthologous region on mouse chromosome 5G: the lowcopy repeats that flank the Williams-Beuren syndrome deletion arose at breakpoint sites of an evolutionary inversion(s). Genomics 2000;69:1-13

-4 Bellugi U, Lichtenberger L, Jones W, Lai Z, St George M: I. The neurocognitive profile of Williams syndrome: a complex pattern of strengths and weaknesses. J Cogn Neurosci 2000;12:7-29.

-5 Jarvinen-Pasley A, Bellugi U, Reilly J, Mills DL, Galaburda A, Reiss AL, Korenberg JR: Defining the social phenotype in Williams syndrome: a model for linking gene, the brain, and behavior. Dev Psychopathol 2008; 20:1-35

-6 Martens MA, Wilson SJ, Reutens DC: Research Review: Williams syndrome: a critical review of the cognitive, behavioral, and neuroanatomical phenotype. JChild Psychol Psychiatry 2008;49:576-608.

7 Ewart AK, Morris CA, Atkinson D, Jin W, Sternes K, Spallone P, Stock AD, Leppert M, Keating MT: Hemizygosity at the elastin locus in a developmental disorder, Williams syndrome. Nat Genet 1993;5:11-16.

-8 Doyle TF, Bellugi U, Korenberg JR, Graham $\mathrm{J}$ : 'Everybody in the world is my friend' hypersociability in young children with Williams syndrome. Am J Med Genet A 2004; 124:263-273.
9 Giordano U, Turchetta A, Giannotti A, Digilio MC, Virgilii F, Calzolari A: Exercise testing and 24-hour ambulatory blood pressure monitoring in children with Williams syndrome. Pediatr Cardiol 2001;22:509-511.

10 Daniels SR, Loggie JM, Schwartz DC, Strife JL, Kaplan S: Systemic hypertension secondary to peripheral vascular anomalies in patients with Williams syndrome. J Pediatr 1985;106:249-251.

11 Ewart AK, Morris CA, Ensing GJ, Loker J, Moore C, Leppert M, Keating M: A human vascular disorder, supravalvular aortic stenosis, maps to chromosome 7. Proc Natl Acad Sci USA 1993;90:3226-3230.

12 O'Connor WN, Davis JB Jr, Geissler R, Cottrill CM, Noonan JA, Todd EP: Supravalvular aortic stenosis. Clinical and pathologic observations in six patients. Arch Pathol Lab Med 1985;109:179-185.

13 Rein AJ, Preminger TJ, Perry SB, Lock JE, Sanders SP: Generalized arteriopathy in Williams syndrome: an intravascular ultrasound study. J Am Coll Cardiol 1993;21: $1727-1730$.

14 Tassabehji M, Metcalfe K, Donnai D, Hurst J, Reardon W, Burch M, Read AP: Elastin: genomic structure and point mutations in patients with supravalvular aortic stenosis. Hum Mol Genet 1997;6:1029-1036.

15 Panayiotopoulos YP, Tyrrell MR, Koffman G, Reidy JF, Haycock GB, Taylor PR: Midaortic syndrome presenting in childhood. $\mathrm{Br}$ J Surg 1996;83:235-240.

16 Pober BR, Johnson M, Urban Z: Mechanisms and treatment of cardiovascular disease in Williams-Beuren syndrome. J Clin Invest 2008;118:1606-1615.
17 Bayarsaihan D, Dunai J, Greally JM, Kawasaki K, Sumiyama K, Enkhmandakh B, Shimizu N, Ruddle FH: Genomic organization of the genes Gtf2ird1, Gtf2i, and Ncf1 at the mouse chromosome 5 region syntenic to the human chromosome 7q11.23 Williams syndrome critical region. Genomics 2002;79: 137-143.

18 DeSilva U, Elnitski L, Idol JR, Doyle JL, Gan W, Thomas JW, Schwartz S, Dietrich NL, Beckstrom-Sternberg SM, McDowell JC, Blakesley RW, Bouffard GG, Thomas PJ, Touchman JW, Miller W, Green ED: Generation and comparative analysis of approximately 3.3 Mb of mouse genomic sequence orthologous to the region of human chromosome 7q11.23 implicated in Williams syndrome. Genome Res 2002;12:3-15.

19 Li HH, Roy M, Kuscuoglu U, Spencer CM, Halm B, Harrison KC, Bayle JH, Splendore A, Ding F, Meltzer LA, Wright E, Paylor R, Deisseroth K, Francke U: Induced chromosome deletions cause hypersociability and other features of Williams-Beuren syndrome in mice. EMBO Mol Med 2009;1:5065.

20 Li DY, Brooke B, Davis EC, Mecham RP, Sorensen LK, Boak BB, Eichwald E, Keating MT: Elastin is an essential determinant of arterial morphogenesis. Nature 1998;393:276280.

21 Mecham RP: Overview of extracellular matrix. Curr Protoc Cell Biol 2001;10:10-11.

22 Wolinsky H, Glagov S: A lamellar unit of aortic medial structure and function in mammals. Circ Res 1967;20:99-111.

23 Li DY, Faury G, Taylor DG, Davis EC, Boyle WA, Mecham RP, Stenzel P, Boak B, Keating MT: Novel arterial pathology in mice and humans hemizygous for elastin. J Clin Invest 1998;102:1783-1787.

24 Wagenseil JE, Mecham RP: Vascular extracellular matrix and arterial mechanics. Physiol Rev 2009;89:957-989. 
25 Dridi SM, Foucault Bertaud A, Igondjo Tchen S, Senni K, Ejeil AL, Pellat B, Lyonnet S, Bonnet D, Charpiot P, Godeau G: Vascular wall remodeling in patients with supravalvular aortic stenosis and Williams Beuren syndrome. J Vasc Res 2005;42:190-201.

-26 Faury G, Pezet M, Knutsen RH, Boyle WA, Heximer SP, McLean SE, Minkes RK, Blumer KJ, Kovacs A, Kelly DP, Li DY, Starcher B, Mecham RP: Developmental adaptation of the mouse cardiovascular system to elastin haploinsufficiency. J Clin Invest 2003;112: 1419-1428.

-27 Wagenseil JE, Nerurkar NL, Knutsen RH, Okamoto RJ, Li DY, Mecham RP: Effects of elastin haploinsufficiency on the mechanical behavior of mouse arteries. Am J Physiol Heart Circ Physiol 2005;289:H1209-H1217.

28 Jordan C, Li HH, Kwan HC, Francke U: Cerebellar gene expression profiles of mouse models for Rett syndrome reveal novel MeCP2 targets. BMC Med Genet 2007;8:36.

-29 Goergen CJ, Johnson BL, Greve JM, Taylor CA, Zarins CK: Increased anterior abdominal aortic wall motion: possible role in aneurysm pathogenesis and design of endovascular devices. J Endovasc Ther 2007; 14: 574-584.

30 Humphrey JD, Delange SL: An Introduction to Biomechanics: Solids and Fluids, Analysis and Design. New York, Springer, 2004.

-31 Peterson L, Jensen R, Parnell J: Mechanical properties of arteries in vivo. Circ Res 1960; 8:622-639.
\$2 Kawasaki T, Sasayama S, Yagi S, Asakawa T, Hirai T: Non-invasive assessment of the age related changes in stiffness of major branches of the human arteries. Cardiovasc Res 1987;21:678-687.

33 Dietz HC, Mecham RP: Mouse models of genetic diseases resulting from mutations in elastic fiber proteins. Matrix Biol 2000;19: 481-488.

34 Nakamura T, Lozano PR, Ikeda Y, Iwanaga Y, Hinek A, Minamisawa S, Cheng CF, Kobuke K, Dalton N, Takada Y, Tashiro K, Ross J Jr, Honjo T, Chien KR: Fibulin-5/DANCE is essential for elastogenesis in vivo. Nature 2002;415:171-175

35 Wagenseil JE, Ciliberto $\mathrm{CH}$, Knutsen $\mathrm{RH}$ Levy MA, Kovacs A, Mecham RP: Reduced vessel elasticity alters cardiovascular structure and function in newborn mice. Circ Res 2009; 104:1217-1224.

36 Davis EC: Elastic lamina growth in the developing mouse aorta. J Histochem Cytochem 1995;43:1115-1123.

37 Del Campo M, Antonell A, Magano LF, Munoz FJ, Flores R, Bayes M, Perez Jurado LA Hemizygosity at the NCF1 gene in patients with Williams-Beuren syndrome decreases their risk of hypertension. Am J Hum Genet 2006;78:533-542.

38 Jackson ZS, Dajnowiec D, Gotlieb AI, Langille BL: Partial off-loading of longitudinal tension induces arterial tortuosity. Arterioscler Thromb Vasc Biol 2005;25:957-962.

-39 Lanne T, Sonesson B, Bergqvist D, Bengtsson $\mathrm{H}$, Gustafsson D: Diameter and compliance in the male human abdominal aorta: influence of age and aortic aneurysm. Eur J Vasc Surg 1992;6:178-184.
40 Radford DJ, Pohlner PG: The middle aortic syndrome: an important feature of Williams' syndrome. Cardiol Young 2000;10:597-602.

41 Urban Z, Riazi S, Seidl TL, Katahira J, Smoot LB, Chitayat D, Boyd CD, Hinek A: Connection between elastin haploinsufficiency and increased cell proliferation in patients with supravalvular aortic stenosis and WilliamsBeuren syndrome. Am J Hum Genet 2002; 71:30-44.

42 Vaideeswar P, Shankar V, Deshpande JR, Sivaraman A, Jain N: Pathology of the diffuse variant of supravalvar aortic stenosis. Cardiovasc Pathol 2001;10:33-37.

$\checkmark 43$ Van Son JA, Edwards WD, Danielson GK: Pathology of coronary arteries, myocardium, and great arteries in supravalvular aortic stenosis. Report of five cases with implications for surgical treatment. J Thorac Cardiovasc Surg 1994;108:21-28.

44 Pezet M, Jacob MP, Escoubet B, Gheduzzi D, Tillet E, Perret P, Huber P, Quaglino D, Vranckx R, Li DY, Starcher B, Boyle WA, Mecham RP, Faury G: Elastin haploinsufficiency induces alternative aging processes in the aorta. Rejuvenation Res 2008;11:97-112.

45 Amenta F, Cavallotti C, Ferrante F, Zomparelli $\mathrm{M}$ : The cholinergic innervation of the aorta. Acta Histochem 1980;66:197-203.

46 Grigor'eva TA: The Innervation of Blood Vessels. New York, Pergamon, 1962.

47 Russell A, Watts S: Vascular reactivity of isolated thoracic aorta of the C57BL/6J mouse. J Pharmacol Exp Ther 2000;294:598-604. 